\title{
Introduction to Automobile Marketing Technology Curriculum Reform
}

\author{
Fang Zhai \\ Beijing Fengtai District By Huaxiang Xinzhuang No. 90 \\ Beijing institute of information technology for the southern district of automotive engineering \\ Beijing, China \\ zhaif@bitc.edu.cn
}

\begin{abstract}
This article around the automobile marketing technology core curriculum teaching reform, widely listen to the opinions of the previous graduates, in view of the poor teaching effect, such problems as theoretical teaching abstract improvement methods are put forward.
\end{abstract} reform

Keywords- automobile marketing technology curriculum

Vocational colleges of the curriculum reform is not others, but all the vocational education teachers should be thinking about. Ourautomotive engineering technology and marketing professional core courses the auto marketing operation technology, five years have passed, the existing course materials have tend to be more perfect. But as the students come from falling, and the basis of students study enthusiasm next term. Classroom teachers think they try to lessons to complete the tasks in class, but no good effect; And not practical nor interest in students think course, led to the widespread disgusted phenomenon. The result is that the pass rate is not high, the contradiction of teaching and learning, the teaching effect is poor, has become a vicious circle. In order to solve this contradiction, the author takes the form of questionnaire, survey, alumni for project tasks in the opinion of this curriculum, curriculum reform preliminary conclusions finally.

\section{THE REFORM OF THE TEACHING CONTENT}

Higher vocational orientation determines its must carry on the reform on teaching content, must be practical and targeted. The author made questionnaire fill in the blanks with the past, asking automotive technology service and marketing professional graduate research, mainly engaged in the work of more than one year sales graduates, solicit their opinions. Please fill out the course they should have the knowledge and skills in the practical work, mark what is negligible, and important content.

Provided by the project task is now nine classes in the following:

1) can correctly describe the car market marketing environment

2) the right to develop car market marketing survey

3) analyze the auto purchase behavior of consumers

4) to segment car market

5) can correctly describe the car product strategy

6) for the automotive product pricing
7) can analyze car product sales channelsCar

8) using the car sales promotion strategy, design product promotion plan

9) car sales skills training

After contact with graduates of communication, finally summary. Summary of the following:

a) item 1), 4), 6),7) strong theoretical, suggest delete or weakened;

b) item 2) the need to strengthen the writing ability and PPT production ability;

c) item 3) using case teaching method, each other between the classmate scene simulation increases learning effect; Accurate analysis of the type of customer;

d) item 5) should know more about car brand culture, the history of the brand; The advantages and disadvantages of various models, know more about competing goods vehicles, to master its advantages and disadvantages;

e) item 8) according to the models of brand, combined with different populations to specify different promotion strategy;

f) item 9) to establish good relationship with customers, will analyze the customer type;Improve your language charm and charisma, no not sell products, not only sell sales!

By graduates feedback from a line of work, for the next to provide a basis for the reform of teaching content. Automobile marketing technology this course has the characteristics of practicality, practicability, real time, the teacher must be based on a certain theory, timely supplement course of new knowledge, new technology, new regulations, new content, to enrich the teaching content, improve teaching effect.

\section{THE METHOD OF REFORM}

Higher vocational teaching reform is an important link is the reform of teaching methods and means, to practical applications, such as automobile marketing technology class curriculum is particularly important. Now the course mainly driven by tasks, scene simulation, several teaching, case teaching method has yet to be improved and enhanced. The author in teaching law adopted some new attempt, has obtained the certain effect.

A. Import type teaching throughout the course

Courses with "do you like model" for the introduction, 
in every chapter involves models related issues. Guide students with questions to study, such as "model is how to position do you like?"'How do you like models for marketing?"Before, this method is applied to theoretical level, in the actual models introduced models designated by the teacher to explain, it's not obvious. Now use scenario simulation training class introduced their own cars, so improve the students' study enthusiasm, enhances the student to study models of autonomy, become passive to active. Highlight the practicability of teaching content, improving the teaching effect.

\section{B. Class presentation method to consolidate the basic knowledge}

This course requires students to have a strong ability of language communication, therefore the teacher arranged in each class within 5 minutes before the class presentation by the students. Content around their favorite models, including car culture, competition, new style, and so on is introduced. Such communication on the one hand, improve the students' expression strain capacity, exercise the psychological quality; On the other hand, students in the process of preparing materials could improve the ability of information processing, enrich the teaching content at the same time, active classroom atmosphere.

\section{Able to match, in order to promote teaching}

In recent years, vocational skills contest with conventional teaching cohesion has become a vocational education teaching reform in theory and practice of pioneering exploration project. Skills competition through competition project check whether vocational colleges highlights the characteristics of the vocational education, attention to the cultivation of comprehensive ability, especially the practice ability. Department of automotive engineering has from tifert frequently take part in higher vocational vocational skills automobile marketing competition, and won the second and third prizes in Beijing good grades. But every year is the pre-competition training, students classes, teachers training and complete the entire work overtime. The author put forward to promote professional competition project teaching method preliminary idea, namely the classroom teachers in the practice teaching, in the form of competition, organizes the student to complete the project tasks, and included in the final examination results. So we can put the skills contest routinization, lets the student feel skills contest is close to their industry. Classroom teachers to actively participate in, in the daily teaching students, found that the great potential of cultivating students, preparing for the skills contest.

\section{CHANGE OF TEACHING IDEAS}

Nowadays the vocational school students naughty, active, do not love learning, the class like to play with mobile phones, see the video. I've been thinking about and want to improve this state, finally in Beijing institute of information technology organizations from Singapore nanyang institute of technology, senior lecturer Chen Yiping "the effective way of teaching and learning" lecture found the answer.

She talked about video games can let students find in reality can not find a sense of achievement and satisfaction. When it comes to why addictive, she talk of people is necessary, in will not get the best of times good instead of as a condition, can lead to a vicious cycle. Best for good, she also made the explanation. People need to drink plain boiled water, for example, this is normal, but she didn't find water, with wine instead of, the more you feel thirsty, finally become addicted. She says teachers can take to teach content is divided into several blocks, easy to accept students with poor ability to accept, each have a bit progress is encouraging, divided into blocks is also looking for more praise.

Face reality curriculum, teachers should change identity, from the traditional knowledge into the organizers of the students' learning. Teachers for students to learn the organizers of an important task is to provide students with cooperation and exchange of time and space. Teachers should "teacher way dignity" get out of the shelf, become a student activities of the participants. Teachers to squat down to see the students, this is a kind of humanistic concern, is also a kind of respect. Fully integrated into the students, cooperation and communication with students, build the classroom atmosphere conducive to the development of individual character, make students obtain new knowledge and ability effectively. Only the equality between teachers and students, can arouse the enthusiasm of the cooperation between teachers and students, is advantageous to the communication between teachers and students.

\section{THE TERM}

Vocational school curriculum reform is not a simple combination of the word, change form and substance does not change, but to explore a method more suitable for students, make students learn more, to better adapt to society and make more contribution for the society.

\section{REFERENCE}

[1]NiHong higher vocational teaching reform of automobile marketing thinking and exploring "coastal enterprises and science and technology" the 10th, 2008 